\title{
ENVIRONMENTAL EMISSIONS FROM ENERGY TECHNOLOGY SYSTEMS: THE TOTAL FUEL CYCLE
}

\author{
By Dr. Robert L. San Martin \\ Deputy Assistant Secretary for Renewable Energy \\ U.S. Department of Energy \\ Washington, DC, U.S.A.
}

Spring, 1989 


\section{DISCLAIMER}

This report was prepared as an account of work sponsored by an agency of the United States Government. Neither the United States Government nor any agency Thereof, nor any of their employees, makes any warranty, express or implied, or assumes any legal liability or responsibility for the accuracy, completeness, or usefulness of any information, apparatus, product, or process disclosed, or represents that its use would not infringe privately owned rights. Reference herein to any specific commercial product, process, or service by trade name, trademark, manufacturer, or otherwise does not necessarily constitute or imply its endorsement, recommendation, or favoring by the United States Government or any agency thereof. The views and opinions of authors expressed herein do not necessarily state or reflect those of the United States Government or any agency thereof. 


\section{DISCLAIMER}

Portions of this document may be illegible in electronic image products. Images are produced from the best available original document. 


\title{
ENVIRONMENTAL EMISSIONS FROM ENERGY TECHNOLOGY SYSTEMS: THE TOTAL FUEL CYCLE
}

\author{
By Dr. Robert L. San Martin \\ Deputy Assistant Secretary for Renewable Energy \\ U.S. Department of Energy \\ Washington, DC, U.S.A.
}

Spring, 1989 


\section{ENVIRONMENTAL EMISSIONS FROM ENERGY TECHNOLOGY SYSTEMS: THE TOTAL FUEL CYCLE}

- Abstract

- Introduction

- Analysis Concept

- Emission Analysis and Comparison by Energy Production Stage

- $\mathrm{CO}_{2}$ Emissions Summary

- Renewable Energy $\mathrm{CO}_{2}$ Displacement Projections

- Conclusion

\section{Abstract}

To accurately quantify and compare environmental emissions from energy technologies, each phase of the fuel cycle, including resource extraction, facility construction and facility operation, must be evaluated. Meaningful comparisons among the various technologies should also be based on a common measure of each technology's useful output. This analysis establishes a framework for conducting a comparative evaluation of the total fuel cycle of different energy technologies. Environmental considerations for each technology and each phase of the fuel cycle, categorized by major types such as air emissions, water emissions, solid waste emissions and materiel requirements, are evaluated individually for different environmentally significant substances.

The result is a comparative analysis of 14 electric generating technologies using the total energy cycle framework and metric tons per gigawatt hour (GWh) as a consistent unit of measurement for comparison.

\section{Introduction}

The analysis presented in this paper examines environmental factors by building on a previous study conducted for the U.S. Department of Energy's Office of Renewable 
Energy, Energy System Emissions and Materiel Requirements, ${ }^{1}$ which developed an overall methodology for direct comparison of electric power technologies. That assessment viewed all environmental impacts associated with a technology as part of a total system designed to extract and produce energy over a specified operating life. By relating environmental emissions from the resource extraction, facility construction, and facility operation phases, a basis was established for comparing electric technologies that have different capital, fuel, and operating characteristics. The five electric power technologies evaluated were:

- a conventional pulverized coal plant

- an Atmospheric Fluidized Bed Combustion (AFBC) plant

- an Integrated Gasification Combined Cycle (IGCC) plant

- a boiling water nuclear reactor

- a central station photovoltaic plant

The earlier work evaluated more than 30 environmental factors including atmospheric emissions such as carbon dioxide $\left(\mathrm{CO}_{2}\right)$ and nitrogen oxide $\left(\mathrm{NO}_{\mathrm{x}}\right)$; water emissions such as dissolved solids; solid waste; and land and water requirements; all reported on the basis of quantities per unit of electric output (e.g. tons/GWh).

This paper builds upon the earlier report by expanding the number of energy technologies compared. Fossil fuel technologies included in this analysis are:

- a conventional pulverized coal plant

- an Atmospheric Fluidized Bed Combustion (AFBC) plant

- an Integrated Gasification Combined Cycle (IGCC) plant

- an oil-fired steam electric plant

- a gas-fired steam electric plant

The non-fossil energy technologies examined include:

- a boiling water nuclear reactor

- a wood-fired steam electric generating station

- an open-cycle Ocean Thermal Energy Conversion (OTEC) plant

- a dry-steam hydrothermal geothermal power station

- a large hydropower plant

- a small hydropower plant

- a wind energy conversion system

- a central station photovoltaic plant

- a distributed receiver solar thermal electric plant 
Among the types of emissions analyzed, carbon dioxide represented one of the most significant quantities of emissions on a per gigawatt-hour basis. Therefore, to illustrate how comparative analyses can be conducted using a total energy cycle methodology, data for $\mathrm{CO}_{2}$ emissions from each of the above technologies will be the focus of this presentation. Also, some studies suggest carbon dioxide, from a combination of fossil fuel combustion and deforestation, accounts for nearly 50\% of the "enhanced" greenhouse effect resulting from increasing concentrations of greenhouse gases. ${ }^{2}$

\section{Analysis Concept}

Because this analysis attempts to take a detailed, directly comparative view of emissions from power production technologies, only limited data were readily available. For the most part the literature on emissions of electric technologies tends to focus on power production. Emissions associated with extraction and transportation of fuel, or associated with plant construction, have been less fully documented and the available literature is limited with respect to the relationship to point-of-use characterizations. The National Acid Precipitation Assessment Program (NAPAP) has made important progress in addressing integrated fuel cycles and identifying data gaps. Most do not address the effects of fuel extraction and facility construction. As a result of these limitations this analysis is restricted to examining major issues using data from available sources.

This analysis does not seek to recommend one technology over another. Rather, it is intended to provide a useful comparison of each technology's emissions profiles, which is only one factor that should be considered in their deployment. Without information on costs, the suitability of a technology to particular sites and energy demand situations, and other environmental impacts associated with particular projects, it is impossible to say one technology is preferable to another.

\section{Study Approach}

The analysis used in this paper is based on two fundamental considerations. First, the environmental effects of energy production at all stages of the energy production cycle must be viewed as a direct function of generating the final energy product. Only by analyzing the complete energy cycle can these effects be fully and consistently evaluated. The second consideration requires that a common measure of the environmental factors be established such that the total energy cycle for different technologies can be cross-compared within specific categories of emissions, while controlling for variation in energy output, materiel requirements, fuel demand, etc.

By investigating the impact of each stage of the energy production process, the analysis attempts to normalize differences between materiel- and fuel-intensive 
technologies in order to provide a fair basis for comparison. When emissions are normalized in terms of each facility's useful power output, the association between electricity production and emissions for each technology becomes clearer.

$\mathrm{CO}_{2}$ emissions are rarely expressed in terms of quantities as a function of useful power output, largely because $\mathrm{CO}_{2}$ has never been regulated or measured as an air pollutant. Raw tonnages of $\mathrm{CO}_{2}$ only indirectly show the impact of the product society actually consumes -- watt-hours of electricity.

This study estimates $\mathrm{CO}_{2}$ emissions associated with each stage of energy production for each technology as part of one system designed to produce energy, from fuel extraction through construction, operation, and decommissioning. The goal of this approach is to make the impact of a technology like photovoltaics, which has practically no emissions during operation, but requires significant one-time inputs of raw materiel, comparable to emissions from a technology like a coal plant, which produces its most significant emissions during operation.

By necessity the comparisons presented are generalizations. Each energy facility is to some extent unique. For example, the amount of steel and concrete used in a PV facility will vary with site conditions and the type of equipment used. Coal mining impacts depend on the extent and depth of deposits, site conditions, and mining methods. Combustion emissions from coal are impacted by both generating equipment and coal chemistry, which varies from mine to mine. Some issues, such as the impact of iron ore mining associated with the steel used in plant construction, were not addressed. The following section discusses and compares the impact of resource extraction, facility construction and plant operation for the fossil fuel, nuclear, and renewable energy technologies examined.

\section{Emission Analysis and Comparison by Energy Production Stage}

Comparing nuclear and renewable energy to the coal technologies confirms the generally accepted belief that non-fossil technologies represent an advantage from the standpoint of $\mathrm{CO}_{2}$ emissions. The results also clearly show, however, that their contribution is not zero when all the elements of their fuel cycle are considered. No technology is completely environmentally benign. The $\mathrm{CO}_{2}$ emissions from the power production technologies examined are shown in Table 1.

\section{Fuel Extraction}

Fossil Fuel Extraction - The fuel extraction stage for fossil fuel includes the impacts of mining, processing, and transporting fuel to the site where it will be converted to energy. Emissions associated with fuel extraction and transportation for the fossil fuel 
Table 1. Carbon Dioxide Emissions: Electric Technologies

Emissions by Energy Production Stage

(Metric Tons per GWh)

Technologies

Conventional Coal Plant

AFBC Plant

IGCC Electric Plant

Oil Fired Plant

Gas Fired Plant

Ocean Thermal Energy Conversion

Geothermal Steam

Small Hydropower ${ }^{*}$

Boiling Water Reactor

Wind Energy

Photovoltaics

Solar Thermal

Large Hydropower

Wood (sustainable harvest)
Fuel Extraction Construction Operation

1.0

1.0

1.0

-

-

NA

0.3

NA

1.5

NA

NA

NA

NA

$-1509.1$
1.0

1.0

1.0

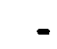

$-$

- $\quad 484.0$

3.7

1.0

10.0

1.0

7.4

5.4

3.6

3.1

2.9
962.0

960.9

748.9

726.2

300.3

55.5

NA

5.3

NA

NA

NA

NA

1346.3
Total

964.0

962.9

750.9

726.2

484.0

304.0

56.8

10.0

7.8

7.4

5.4

3.6

3.1

$-159.9$

$(-)$ Missing or inadequate data for analysis, estimated to contribute $\leq 1 \%$.

(NA) Not Applicable

-This analysis considered construction of new dams. According to a recent Federal Energy Regulatory Commission report there is $8,000 \mathrm{MW}$ of small hydropower under construction or projected, much of it involving refurbishing or refitting existing dams, which would substantially reduce small hydropower's $\mathrm{CO}_{2}$ impact.

technologies were scaled to the fuel demands of each fossil fuel technology by dividing the annual fuel demand of the power plant by the capacity of the fuel extraction, processing, and transportation facilities. This demand/output ratio was multiplied by the emissions from each fuel supply facility to derive the share of emissions from the facility attributable to the final generating plant. For coal it was assumed that the fuel supplied to each technology was mined and transported under the same conditions, so variations in emissions from fuel extraction are mainly a function of each plant's relative efficiency in generating electricity. ${ }^{3}$ Oil and gas fuel extraction data were not complete so the impact of fuel extraction activity could not be assessed. 
Renewable Energy Fuel Extraction -- Most of the renewable energy technologies, including photovoltaics, solar thermal, wind, hydropower, and ocean thermal energy conversion (OTEC) have no direct fuel extraction impacts. Geothermal field development and well drilling activities emit minor amounts of $\mathrm{CO}_{2}$ as a result of gas released from wells.

Biomass energy can produce net reductions in $\mathrm{CO}_{2}$ over the life of the facility assuming that fuel is extracted from a sustainable, managed source of biomass such as a short-rotation, intensive-culture wood plantation, which is examined here. Sustainable biomass energy production will fix $\mathrm{CO}_{2}$ equal to the amount of $\mathrm{CO}_{2}$ released through combustion over the life of the plant. Sources of $\mathrm{CO}_{2}$ emissions external to this cycle, notably from inputs of fertilizers and pesticides and the use of fossil fuels in cultivating, harvesting, and transporting the fuel, were evaluated and included in the analysis as net contributors to $\mathrm{CO}_{2}$ emissions. However, these emissions, are offset by the carbon storage capacity of the roots and other unharvested portions of the biomass that remain in place (and growing in the case of coppiced species). Over the life of a generating plant this harvest/regrowth cycle can yield a net reduction in $\mathrm{CO}_{2}$ emissions over all stages of biomass-fired electricity production.

\section{A Scenario of Biomass Fuel Regrowth}

A managed, short-rotation forest fixes or sequesters 45 metric tons of carbon per hectare per year ( 165 metric tons $C_{2} O_{2}$ per hectare per year) duning its growth period. If trunks and branches from the short-rotation forest are harvested and used in a power plant, 82.5 metric tons of $\mathrm{CO}_{2}$ per hectare remain in the forest, stored in the root system and soil. Therefore, even with harvesting and energy production, substantial carbon remains fixed after the first harvest. Subsequent harvests and wood utilization would be balanced from a $\mathrm{CO}_{2}$ standpoint in that growth of new trunks and branches would offset CO2 released back to the atmosphere during combustion.

In 1986, US. fossilfired electricity production emitted 1.62 bilion metric tons of $\mathrm{CO}_{2}$. Thus, it would require 9.88 million hectares (approximately the size of the state of Virginia) of newly planted forest to offset all 1.62 billion metric tons of $\mathrm{CO}_{2}$. Each tree offsets approximately 338 kilograms ( $\left(0.34\right.$ metrie tons) of $\mathrm{CO}_{2}$ per year during its annual growth cycle. At that recapture rate, 4.8 billion new short rotation trees would need to be planted to absorb the 1.62 billion metric tons of CO2 21986 . With a population in the US. of 240 million, each person would have to plant approximately 20 trees to achieve this offset. (At CO2 offset rates for natural forests, 26 million hectares would be required to uptake 1.62 billion metric tons of $\mathrm{CO}_{2}$ or each person would plant over 50 trees? 
Nuclear Fuel Extraction -- The nuclear calculations were made in the same general manner as the coal calculations, with fuel demand at the power plant traced back through fuel fabrication, enrichment, processing, and mining in order to allocate the emissions from each stage of fuel manufacture in proportion to each stage's contribution to final power production. ${ }^{4}$ An additional increment to emissions was added to the source values based on each fuel processing facility's electricity demand. A coefficient for $\mathrm{CO}_{2}$ emissions as a function of the electric generating fuel mix in the U.S. was calculated and then applied to the electricity demand of the nuclear plant.

\section{Construction}

The construction phase includes the indirect impacts of the technologies in terms of $\mathrm{CO}_{2}$ emissions associated with manufacturing the raw materiel inputs. Steel and concrete are the major materiel inputs examined and the major sources of $\mathrm{CO}_{2}$ emissions.

The construction stage accounts for the greatest differences between materielversus fuel-intensive technologies, with the former producing the highest environmental impacts at this stage. The estimates in this analysis focus exclusively on emissions from final manufacture of major materiel used in construction; it does not represent a comprehensive estimate of all emissions. There are secondary emissions associated with the mining of raw materiel (such as iron ore, bauxite, etc.) and actual in situ assembly of materiel and components, but these types of impacts were not addressed.

The emissions associated with materiel manufacture were divided by the annual output of the technology times the operational life of the technology to derive $\mathrm{CO}_{2}$ emissions per unit of output over plant life. The $\mathrm{CO}_{2}$ emission factor for steel was derived by examining fuel demand as a function of industry output, and then multiplying the resultant estimate of fuel use per ton of output times a $\mathrm{CO}_{2}$ emission coefficient to derive an estimate of $\mathrm{CO}_{2}$ per ton of output. This estimate was then used to calculate the $\mathrm{CO}_{2}$ emissions associated with steel demands. Electricity as an energy input to steel was converted to $\mathrm{CO}_{2}$ inputs by calculating the fuel mix for electricity in 1987, multiplying the quantities by their respective coefficients, and then allocating the gross $\mathrm{CO}_{2}$ emissions over the total number of gigawatt-hours produced in $1987.5,6,7$ The $\mathrm{CO}_{2}$ coefficients for steel, concrete, and for the various fuels considered are based on data from industry data bases or global climate investigations, respectively. $8,9,10$

Fossil Fuel Construction - In the case of the IGCC plant and the AFBC plant, direct estimates of materiel requirements were unavailable. Therefore the values were derived by adjusting the materiel used in a conventional plant by the proportionate capacity associated with the AFBC and IGCC plant. ${ }^{11}$ It is acknowledged that this assumption ignores the significant technology differences and the effects of differing economies of scale between technologies. Data were unavailable for the oil and natural gas plants, and no 
estimates of their impacts were made. In general, emissions from fossil fuel plant construction are small relative to the output over the operating life of the plant.

Renewable Energy Construction -- Like conventional technologies, the materiel requirements for renewable energy plants can vary widely depending on specific site conditions and technical requirements. The different technologies vary widely in their materiel intensity and $\mathrm{CO}_{2}$ emissions per $\mathrm{GWh}$. For each renewable energy technology, the Department of Energy Renewable Energy Program has estimated materiel requirements per MW of capacity, given an "average" or typical facility.

The steel and concrete estimates of a PV plant are for a conceptual utility-scale design developed by the Electric Power Research Institute. The PV plant is assumed to employ flat-plate, thin-film arrays with $15 \%$ efficiency located in Barstow, California. Plant size was $100 \mathrm{MW}$, with $209 \mathrm{GWh}$ of annual energy output. ${ }^{12}$ Geothermal plant construction requirements are basically equivalent to a conventional fossil fuel plant with comparable materiel requirements. The wood combustion generating plant also has construction materiel requirements similar to a comparable fossil plant.

Nuclear Construction - Construction-related $\mathrm{CO}_{2}$ emissions from nuclear energy are quite low when considered over the life of the plant. Although they require a considerable amount of materiel initially, nuclear plant impacts are spread over a high lifetime power output. ${ }^{13}$

\section{Operation}

The values for emissions and materiel inputs associated with operating the technologies were taken from source documents and Renewable Energy Program inputs. The annual value for emissions was then divided by the annual GWh of output for each technology to derive emissions per unit of output. Values for the IGCC and AFBC plants were assumed to be similar to the conventional plant in terms of the rate of emissions, and thus were only adjusted for the increased efficiency and power output per ton of coal input gained from each technology (if any).

Fossil Fuel Plant Operation -- Impacts at the operation stage are measured in terms of emissions produced while the plants are actively generating energy. The conventional coal plant in the assessment is assumed to be a $500 \mathrm{MW}$ facility producing $3500 \mathrm{GWh}$ of electricity annually. It represents a new plant built to meet or exceed existing environmental standards, and to maximize performance. The plant lifetime is assumed to be 30 years, prior to major refurbishment, repowering or retirement.

The AFBC plant examined is rated at $500 \mathrm{MW}$ with annual energy production of $3500 \mathrm{GWh}$. Its useful life is 30 years. Nearly 2 million tons of Illinois coal is required to fuel 
the plant annually. The IGCC plant is rated at $945 \mathrm{MW}$ and produces roughly $6700 \mathrm{GWh}$ annually. The assumed heat rate for the plant is $9,410 \mathrm{~kJ} / \mathrm{kWh}$. Its useful life is 30 years. The plant consumes roughly 3 million tons of coal annually. ${ }^{14}$

The oil-fired plant is rated at $800 \mathrm{MW}$ and produces $3850 \mathrm{GWh}$ annually using 954 million liters of \#6 residual fuel oil. The gas-fired plant is rated at $800 \mathrm{MW}$ and produces $3850 \mathrm{GWh}$ annually using 1.05 billion cubic meters of natural gas annually. Both are conventional steam turbine plants. A combined cycle gas plant would be much more efficient and thus produce lower emissions per useful unit of energy production, but data for an assessment of a combined cycle plant were not available. In general the fossil-fired emissions of $\mathrm{CO}_{2}$ during operation are 962 metric tons per $\mathrm{GWh}$ for conventional coal, over 740 metric tons per GWh for IGCC, 725 metric tons per GWh for oil, and 484 metric tons per $\mathrm{GWh}$ for natural gas.

Renewable Energy Plant Operation -- Hydropower, wind, photovoltaic, and solar thermal technology emissions during plant operation are essentially zero. The wood-fired generating facility has the highest $\mathrm{CO}_{2}$ emissions of any technology during operation but it is important to note that this is offset by fuel regrowth, so that net $\mathrm{CO}_{2}$ emissions are zero, or slightly negative. Among the renewable energy technologies, the OTEC plant has the next highest emissions during operation and the highest overall emissions at 304 tons per GWh. This represents only one OTEC technology option. A closed-cycle system would dramatically reduce the release of entrained gas in the seawater as it is flashed, thus bringing OTEC $\mathrm{CO}_{2}$ emissions in line with the other renewable energy technologies. Similarly, the geothermal dry-steam system is also an open-cycle, which allows venting of $\mathrm{CO}_{2}$ trapped in the hydrothermal steam that powers the turbine generator. This open-cycle hydrothermal system produces 56 tons of $\mathrm{CO}_{2}$ per $\mathrm{GWh}$. Closed-cycle flash steam systems and binary-cycle plants would eliminate the majority of these emissions. Binary technology is especially suited to the most abundant moderate temperature resources, and so is likely to play a larger role in future development of geothermal energy.

Nuclear Plant Operation - The nuclear plant is a boiling water reactor design rated at $1000 \mathrm{MW}$, producing $6130 \mathrm{GWh}$ annually over a useful life of 30 years. ${ }^{15}$ The $\mathrm{CO}_{2}$ emissions during nuclear plant operation should be viewed as the high end of a possible range of emissions, since they are based on the assumed operation of fossil fuel backup generators and boilers during normal operation. Under actual operating conditions a nuclear plant can be expected to operate with less reliance on fossil-fired auxiliary systems. It is estimated that a Pressurized Water Reactor (PWR) will have a similar $( \pm 5 \%) \mathrm{CO}_{2}$ profile. Although the PWR requires somewhat less fuel per gigawatt hour, it uses a more highly enriched fuel concentration. 


\section{Carbon Dioxide Emissions Summary}

Summary by Technology

The total $\mathrm{CO}_{2}$ emission profile of each of the technologies is shown graphically in Figure 1.

Fossil Fuels - Conventional coal provides a baseline for comparison of $\mathrm{CO}_{2}$ emissions from electric generating technologies; it is an established technology with well-known characteristics that provide a benchmark for alternatives. The Atmospheric Fluidized Bed Combustion (AFBC) plant represents an innovative alternative to

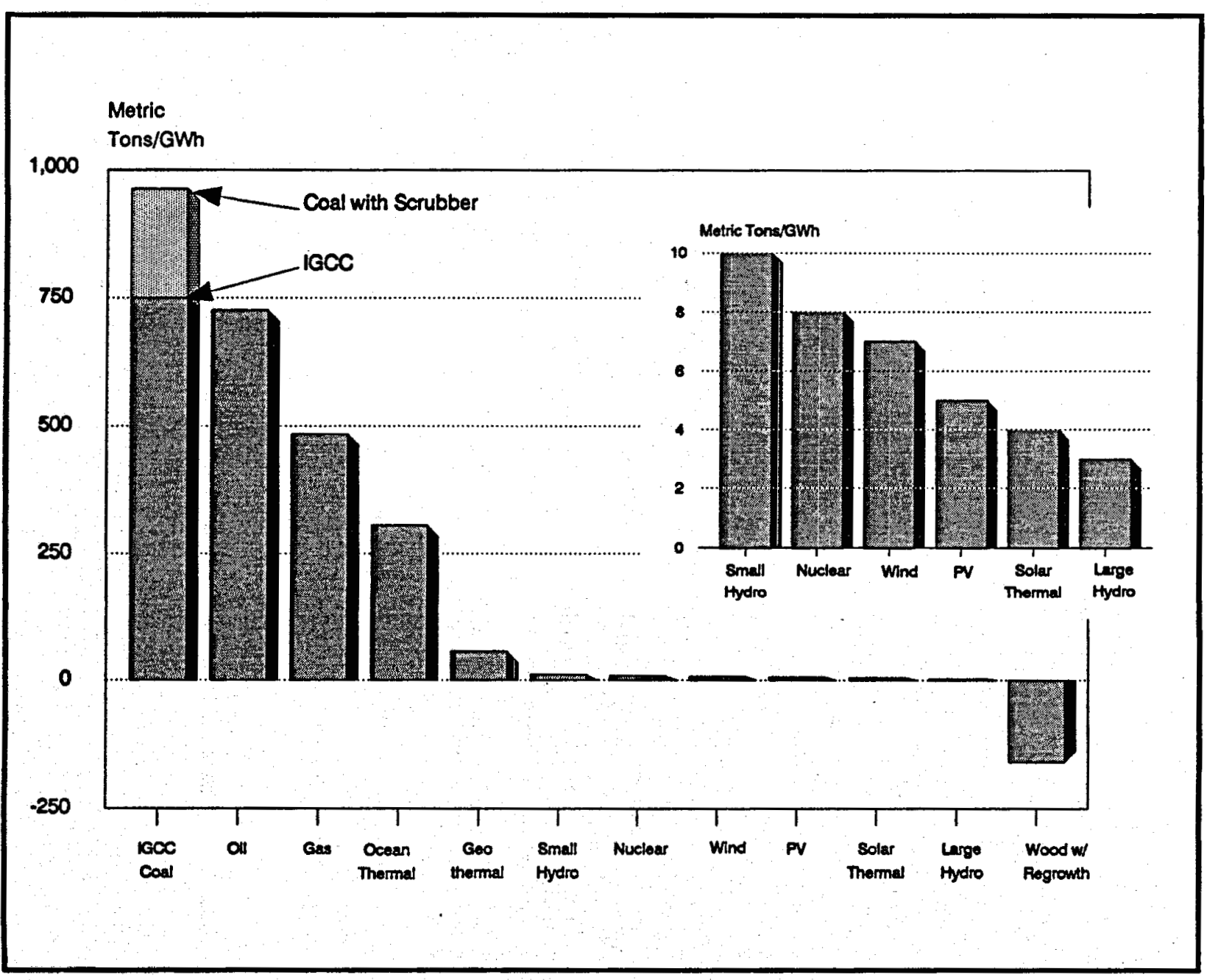

Figure 1. Carbon Dioxide Emissions: Electric Technologies 
conventional coal combustion and scrubbers. ${ }^{16}$ The Integrated Gasification Combined Cycle (IGCC) plant represents an emerging advanced technology which offers significant improvements in coal combustion. ${ }^{17}$ Oil and particularly gas are attractive for their lower $\mathrm{CO}_{2}$ emissions profile, and gas is an increasingly important component of the U.S. electric generating system.

For fossil-fired generating technologies, most $\mathrm{CO}_{2}$ emissions occur during operations. $\mathrm{CO}_{2}$ emissions per ton of coal combusted are assumed to be basically similar for each technology, but the gross emissions are spread over a higher GWh output per ton of coal for the IGCC plant, which accounts for its improved emissions profile. Oil and gas have much lower $\mathrm{CO}_{2}$ emissions per unit of energy output, but still have significantly higher emissions than renewable energy technologies.

Renewable Energy -- $\mathrm{CO}_{2}$ emissions from the hydropower, wind, photovoltaic and solar thermal plant are primarily related to the construction of the generating station and the emissions from the steel and concrete plants. For these technologies, air emissions related to construction are higher than the emissions related to construction for the other technologies because of the materiel-intensive nature of the technology. But overall their emissions are a very small fraction of the emissions from coal technologies and are for the most part less than or comparable to nuclear. Biomass, OTEC, and geothermal have relatively higher emissions during operation. Biomass in particular has higher emissions than a coal plant during operation, but when a managed biomass fuel cycle is considered, which includes regrowth of the feedstock, utilization of wood to produce power can minimize or eliminate net $\mathrm{CO}_{2}$ emissions.

An open-cycle OTEC plant has $\mathrm{CO}_{2}$ emissions comparable to a gas-fired plant during operation, although these emission levels are not inherent in the technology since a closed-cycle could substantially reduce $\mathrm{CO}_{2}$ emissions. Geothermal's emissions during operation are large in comparison to the solar, wind and hydropower technologies, but far less than gas-fired generation. Like OTEC, geothermal $\mathrm{CO}_{2}$ emissions are not inherent in the technology, and could be substantially eliminated through the use of closed-cycle systems.

Nuclear -- $\mathrm{CO}_{2}$ emissions from the nuclear reactor should be viewed as a range, since a portion of the emissions are associated with fossil fuel combustion required to produce electrical and other inputs to uranium processing operations and the occasional use of fossil fuel boilers and generators during operation. There is also an input of fossil fuel to operate backup and auxiliary steam and electricity generators at the plant site during normal refueling and operations. ${ }^{18}$ The effect of these systems varies depending on plant design, the occurrence and extent of planned and unplanned outages, and normal maintenance requirements. 


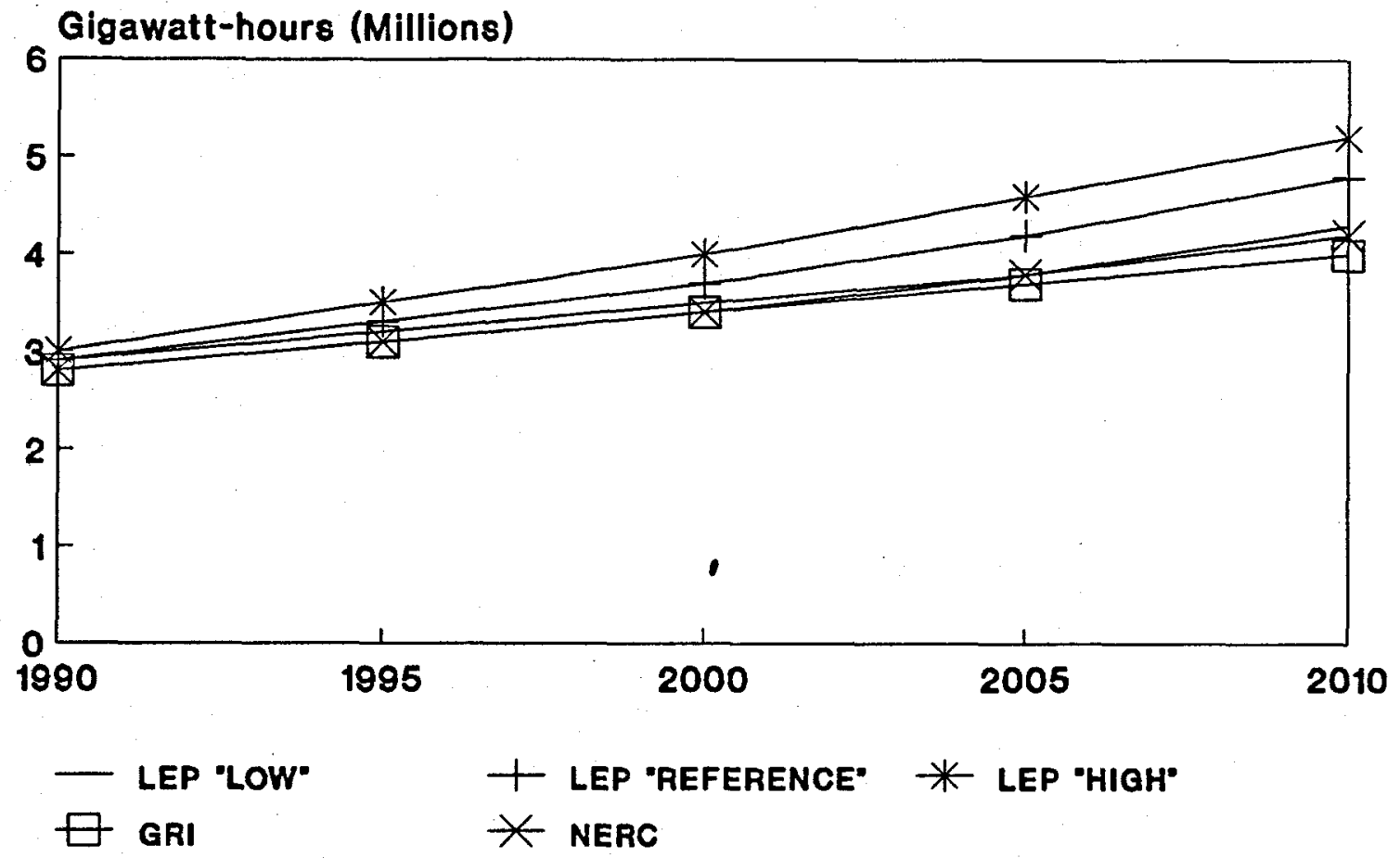

Source: DOE and NERC

Figure 2. Comparisons of Electricity Projections

\section{$\underline{\text { Renewable Energy } \mathrm{CO}_{2} \text { Displacement Projections (A Sample Case) }}$}

\section{Introduction}

While the environmental advantages of renewable energy are evident on a micro level, the following analysis is presented as an illustration of the potential macro impacts of renewable energy technology deployment. The following analysis is based on a DOE projection of energy supply and demand to 2010 and the renewable energy $\mathrm{CO}_{2}$ emission measurements developed in the previous sections of this report. The contribution of renewable energy technologies in power generation is examined to determine the extent to which they will displace both conventional baseload and peaking power generation technologies. The analysis is developed from data contained in the Department of Energy's Long-Range Energy Projections to 2010 (LEP). ${ }^{19}$

Figure 2 shows projections of future electricity contributions based on three LEP scenarios ("High," "Reference," and "Low") along with projections from the Gas Research 
Institute (GRI) and the North American Electric Reliability Council (NERC). Overall, the "reference" case represents the middle range of LEP projections and shows general agreement with utility industry projections, thus it was selected as a reasonable estimate for projected electricity use through the year 2010.

\section{LEP Assumptions}

Electricity consumption is projected to grow in every sector, averaging just over $3 \%$ per year between now and 1990 and between $2.4 \%$ and $2.7 \%$ per year thereafter. The projected growth in electricity consumption is due to a number of factors, including its inherent flexibility, the continuing increases in the efficiency of its end uses and, perhaps most important, the increasing relative prices of oil and natural gas. LEP assumed oil prices in the range of $\$ 18$ and $\$ 22$ per barrel (\$1986) by 1990 . Beyond 1990, price projections are much more uncertain, but are projected to be between $\$ 29$ and $\$ 37$ by 2000 and between $\$ 44$ and $\$ 61$ by 2010.

The electricity consumption projections imply that significant new capital expansion will be required starting in the early 1990 s. By 2000 , according to LEP projections, at least 50 gigawatts (GW) of new generating capacity in addition to the approximately $70 \mathrm{GW}$ currently under construction or announced will be needed. In the LEP "reference" projection, over the near term the bulk of new capacity coming into operation will be coal and nuclear, as plants currently under construction are completed. Much of the new and as yet unplanned generating capacity, anticipated in LEP, is for low-emission coal-fired technologies, with newer "clean coal" technologies such as coal combined cycle and fluidized bed combustion making a growing contribution. Oil use in the electric utility sector is projected to rise, but existing excess oil capacity may negate the need for significant quantities of new conventional oil capacity. Natural gas consumption is also expected to rise, with small amounts of new gas turbine and gas combined-cycle capacity expected. However, by the late 1990 s, oil use is expected to decline due to rising fuel costs, while nuclear expansion is assumed to diminish due to the lack of new plant orders over the past fifteen years. Small hydro, geothermal, wind, and photovoltaic renewable energy facilities are projected to produce moderate but growing amounts of electricity.

In order to determine the potential contribution of renewable energy technologies in displacing future fossil-fired $\mathrm{CO}_{2}$ emissions, fossil-fired electric generating systems were compared with renewable energy systems with similar operating characteristics. It was assumed that gigawatt-hours from hydropower, geothermal, biomass, and ocean thermal production would displace a mix of baseload fossil- and nuclear-generated electricity. Gigawatt-hours generated by wind, photovoltaics, and solar thermal technologies were assumed to displace a mix of intermediate/peaking oil- and gas-fired electricity. 


\section{Net $\mathrm{CO}_{2}$ Displaced by Renewable Energy Technologies}

By the year 2010 renewable energy technologies taken collectively are projected to displace over 8.5 billion metric tons of $\mathrm{CO}_{2}$, on a 24-year cumulative basis, as shown in Table 2 and Figure 3, and would continue to expand substantially beyond 2010. The scenario considered here is based on conservative estimates of future energy use and renewable energy contribution. As the authors of the LEP point out, their scenario(s) should be interpreted simply as points of departure for understanding possible future energy development. The same is true for this analysis of $\mathrm{CO}_{2}$ displacement potential.

Scenarios for renewable energy's contribution in the U.S. could significantly exceed the projections by the LEP, depending on the future price of conventional energy, the overall competitiveness of renewable energy technologies in the future, and the nature and aggressiveness of U.S. and international policy initiatives for addressing global climate change. Advances in renewable energy technology research could greatly accelerate their overall contribution to mitigating $\mathrm{CO}_{2}$ emissions from conventional electric generation technologies.

\section{Conclusion}

In order to compare measures of emissions and materiel requirements for power production technologies, they must be examined in their entirety, taking into account each stage of the energy production process. This comprehensive approach provides a cumulative view of emissions that focuses on quantities of emissions as a function of energy supplied; a measurement convention that facilitates comparisons between different technologies.

From a historical perspective, the mix of fossil-fired electric power generation in the U.S. in 1986 produced an average of 874 metric tons of $\mathrm{CO}_{2} / \mathrm{GWh}$, while renewable energy technologies produced an average of approximately 18 metric tons of $\mathrm{CO}_{2} / \mathrm{GWh}$. Thus each GWh from renewable energy displaced approximately 856 metric tons of $\mathrm{CO}_{2}$, or a $98 \%$ reduction. From a future perspective, projections to 2010 indicate that renewable energy electric technologies could reduce $\mathrm{CO}_{2}$ emissions by 519 million metric tons per year in the U.S., or an $18 \%$ displacement of $\mathrm{CO}_{2}$ related to an equivalent electrical output from fossil-fired power facilities. 
Table 2. Net $\mathrm{CO}_{2}$ Displaced by Technology

(Millions of Metric Tons)

Baseload Renewables

Hydropower

Geothermal

Biomass

Ocean Thermal

1986

1990

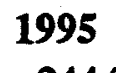

2000

2005

2010

14.7

215.0

244.2

278.3

292.4

296.5

0.9

0.8

36.2

46.1

66.2

80.5

Peaking Renewables

Solar Thermal

0.0

1.7

4.4

6.4

7.3

0.0

0.4

1.4

2.8

Photovoltaics

0.0

0.0

0.6

2.4

4.2

6.6

Wind

0.0

0.0

0.0

2.4

11.4

43.2

x.t.

0.0

6.5

22.0

39.4

70.0

Coniviative ronar

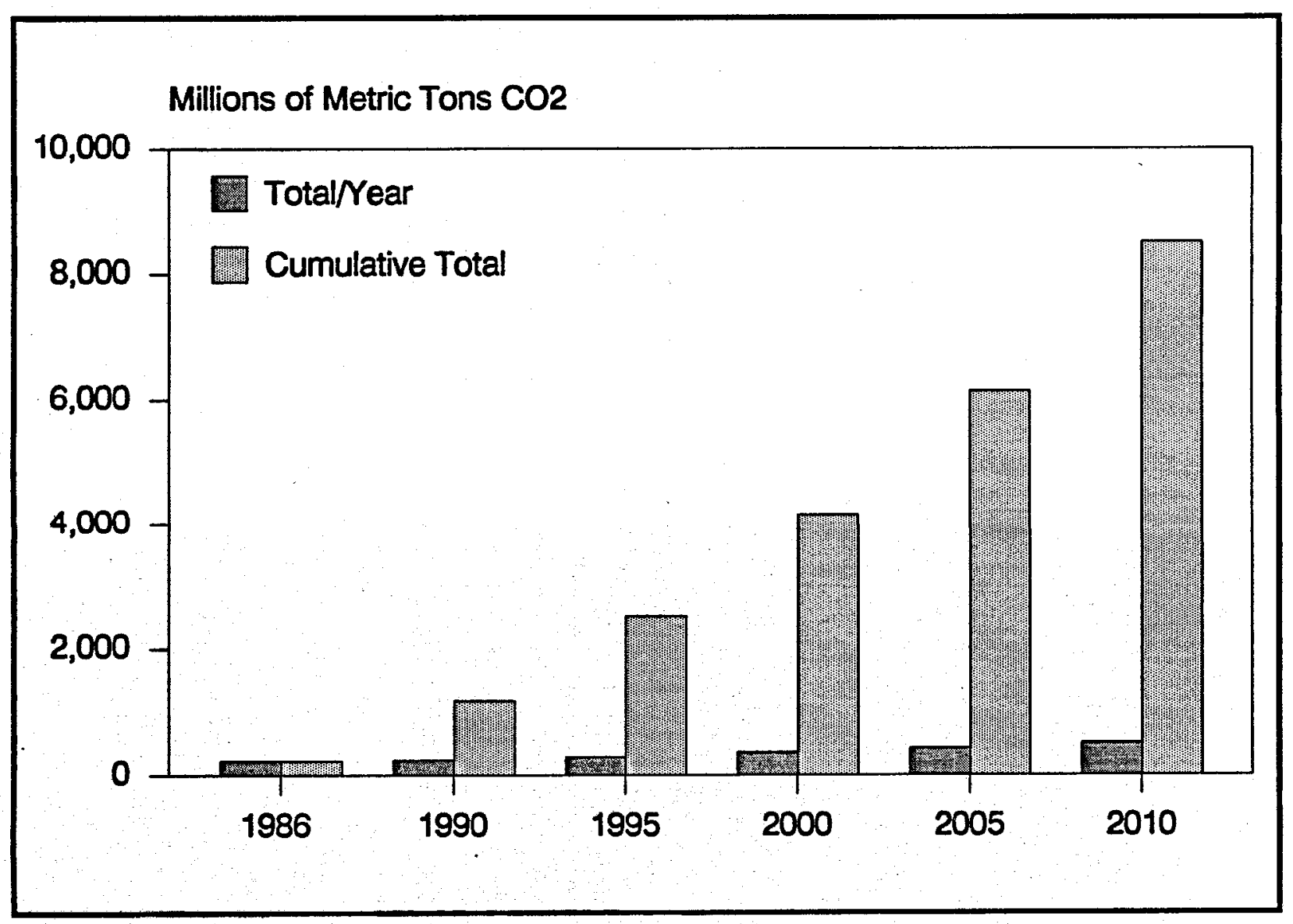

Figure 3. Renewable Energy $\mathrm{CO}_{2}$ Displacement 
Endnotes

1. Meridian Corporation. Energy System Emissions and Materiel Requirements. Prepared for the U.S. Department of Energy Office of Renewable Energy. February, 1989.

2. Rind, Hansen, et al. "A Character Sketch of Greenhouse Gases." EPA Journal. January/February 1989.

3. U.S. Department of Energy. Technology Characterizations: Environmental Information Handbook, DOE/EP--0028. June, 1981, p.76.

4. Ibid., p.2

5. U.S. Department of Energy, Energy Information Administration. Electric Power Monthly. DOE/EIA--0226 (88/06). June, 1988, p. 21.

6. Cheng, H.C., M. Steinberg, and M.Beller. Effects of Energy Technology on Global $\mathrm{CO}_{2}$ Emissions. U.S. Department of Energy, Office of Energy Research.

DOE/NBB--0076. April, 1986 p. 52.

7. Marland G., and R.M. Rotty. $\mathrm{CO}_{2}$ Emissions From Fossil Fuels: $\mathrm{A}$ Procedure for Estimation and Results for 1950-1981. TN: Oak Ridge Associated Universities Incorporated. DOE/NBB--0036. June 1983, p. 13.

8. "Industrial Sector Energy Analysis: The Steel Industry." Gas Energy Review. VA: American Gas Association. vol. 16, no. 11, November, 1988, pp. 6-12.

9. Marland G., and R.M. Rotty. $\mathrm{CO}_{2}$ Emissions From Fossil Fuels: $\mathrm{A}$ Procedure for Estimation and Results for 1950-1981. TN: Oak Ridge Associated Universities Incorporated. DOE/NBB--0036. June, 1983, p. 13.

10. Cheng, H.C., M. Steinberg, and M.Beller. Effects of Energy Technology on Global $\mathrm{CO}_{2}$ Emissions. U.S. Department of Energy, Office of Energy Research. DOE/NBB--0076. April 1986, p. 52.

11. U.S. Department of Energy. Technology Characterizations: Environmental Information Handbook, DOE/EP--0028. June, 1981, p.72.

12. Electric Power Research Institute. Integrated Photovoltaic Central Station Conceptual Designs. Black and Veatch Engineers - Architects for Electric Power Research Institute, EPRI AP-3264, June 1984, p. 3-24. 
13. U.S. Department of Energy. Technology Characterizations: Environmental Information Handbook, DOE/EP--0028. June, 1981, p. 2.

14. U.S. Department of Energy, Office of Fossil Energy. The Role of Repowering in America's Power Generation Future. DOE/FE--0096. December, 1987, p. 9, 15.

15. U.S. Department of Energy. Technology Characterizations: Environmental Information Handbook, DOE/EP--0028. June, 1981, p. 16.

16. U.S. Department of Energy, Office of Fossil Energy. The Role of Repowering in America's Power Generation Future. DOE/FE--0096. December, 1987.

17. U.S. Department of Energy. Technology Characterizations: Environmental Information Handbook, DOE/EP--0028. June, 1981, p. 76.

18. U.S. Department of Energy. Technology Characterizations: Environmental Information Handbook, DOE/EP--0028. June, 1981, appendix p. 29.

19. U.S. Department of Energy, Office of Policy Planning and Analysis. Long Range Energy Projections to 2010. DOE/PE-0082. July, 1988. 